\title{
THE
}

\section{A description of approachable nurses: An exploratory study, the voice of the hospitalized child}

\author{
Bethany J. Petronio-Coia \\ University of Rhode Island \\ Donna Schwartz-Barcott \\ University of Rhode Island, dsbbb@uri.edu
}

Follow this and additional works at: https://digitalcommons.uri.edu/nursing_facpubs

\section{The University of Rhode Island Faculty have made this article openly available.}

Please let us know how Open Access to this research benefits you.

This is a pre-publication author manuscript of the final, published article.

Terms of Use

This article is made available under the terms and conditions applicable towards Open Access

Policy Articles, as set forth in our Terms of Use.

\section{Citation/Publisher Attribution}

Petronio-Coia, B. J., \& Schwartz-Barcott, D. (2020). A description of approachable nurses: An exploratory study, the voice of the hospitalized child. Journal of Pediatric Nursing, 54, 18-23. doi: 10.1016/ j.pedn.2020.05.011 Available at: https://doi.org/10.1016/j.pedn.2020.05.011 


\title{
A description of approachable nurses: An exploratory study, the voice of the hospitalized child, Bethany J. Petronio-Coia, RN, PhD, Donna Schwartz-Barcott, RN, PhD
}

\author{
Abstract \\ Purpose: The 1989 Convention on the Rights of the Child drew international attention to the \\ right of a child to be heard. Researchers have enhanced the child's voice in many settings, albeit \\ few in the hospital. Nurse researchers investigating the hospital experiences of children have \\ identified positive and negative patterns of communication. Potential characteristics of an \\ approachable nurse were hinted at, although none explored the concept of approachability. \\ Design and methods: A qualitative, descriptive research design, including semi-structured \\ interviews with seven school age children (ages 8-12, four girls and three boys) in a pediatric \\ oncology service, was used to gain children's perceptions and descriptions of approachable \\ nurses. Drawings were used to supplement and glean a greater understanding of descriptive \\ characteristics. All but one child had endured multiple hospitalizations related to their diagnosis \\ of cancer. Interviews were recorded and data were content analyzed using \\ immersion/crystallization and editing organizational styles. \\ Results: The children had experiences with more than one approachable nurse and described \\ approachable nurses as smiling and happy, playful, creative, competent and willing to talk and \\ listen to them.
}

Conclusion and practice implications: The school age children in this study were able to describe their perceptions of an approachable nurse. The voices of these children illuminate the importance of nurses' words and behaviors and provide exemplars of approachable nurses. It can be argued that the responsibility remains with nurses to create an environment where in 
hospitalized children feel their voices are heard, they are understood and respected with unprecedented dignity.

Keywords:

approachable; nurses; hospitalized child; pediatric, communication

\section{Introduction:}

The 1989 United Nations Convention on the Rights of the Child drew international attention to the need to protect and promote the rights of children to survive and thrive, to learn and grow, to make their voices heard and to reach their full potential (United Nations Convention on the Rights of the Child, UNCRC, 1989). Emphasizing the treaty's relevance for pediatric health care, Soderback and colleagues explained that "The provision of quality care in health services tailored to children's preferences means that health professionals have a responsibility to ensure children's rights, and that a child is encouraged and enabled to make his or her view known on issues that affect them" (Soderback, Coyne, \& Harder, 2011, p.100). More recently, in 2002, the United Nations held a Special Session of the UN General Assembly on Children, at which many nations of the world committed themselves to a series of goals to improve the situation of children and young people (UN General Assembly on Children, 2002). It is the intent of the United Nations Children's Fund to support the belief that children need to be encouraged and enabled to make their views known on issues that affect them, knowing that the premise of 'A World Fit for Children' will only be accomplished with the full participation of children and young people (UNICEF, 2003). In response to the treaty, a number of researchers have begun to capture the voices of children in relation to many domains of life, except for those of hospitalized children (UN General Assembly on Children, 2002). 
As Boztepe, Cinar and Ay (2017) and others (Coyne, 2006 ; Coyne \& Kirwan, 2012) have pointed out, there is a volume of studies on children's hospital experiences but, almost exclusively from the voices of nurses and parents rather than the children themselves. There are a small number of researchers, however, mainly from Western Europe who have begun to capture the voice of the child in studies of children's experiences during hospitalization In a related body of literature, a small number of researchers, mainly from Western Europe, have begun to capture the voice of the child in studies of children's experiences during hospitalization (Boztepe et al., 2017; Corsano et al. 2015; Coyne, 2006; Coyne and Kirwan, 2012; Pena and Juan, 2011). The key role of nurses in this experience is highlighted in the qualitative metasynthesis of studies considering the voice of the child from 1996 to 2017 (Jepsen, Haahr, Eg \& Jorgensen, 2019).

The role of nurses in this experience, albeit positive or negative, is acknowledged throughout this literature as the researchers focus in on specific aspects of the experience (e.g. child's ability to cope with various treatments or emotional events). A few researchers have included some description of how nurses and children communicated with each other, although none focused specifically on what makes a child feel that a particular nurse is approachable. In a study by Spanish researchers, (Pena \& Juan, 2011), hospitalized children described nurses who communicated well as those who showed empathy with laughter and humor, used child friendly language and told personal stories. In another study by an Irish researcher (Coyne, 2006), children identified pediatric nurses who demonstrated therapeutic communication as those who were supportive, patient, gentle, cheerful, communicated openly and provided privacy. In a subsequent study (Coyne and Kirwan, 2012), children identified supportive nurses as nice, kind, gentle, caring, funny, strict and good listeners. Such descriptions would seem to reflect nurses 
who were highly approachable, although the concept of approachability was not mentioned and there is, to date, no explicit definition of the concept that can be used in relation to pediatric nurses.

In the social psychology literature, researchers have identified approachability as a distinct and important scientific concept when looking at what draws one person to another, especially when that person is a stranger (Miles, 2009; Palermo \& Burke, 2011). In laboratory studies of adults, researchers have found a smiling face to be the most common, key characteristic of someone who is seen as approachable. The aim of this study is to examine the concept of approachability outside a laboratory setting and in relation to the interaction between a hospitalized child- and a nurse on an oncology unity in the United States and from the perception and voice of the child.

\section{Method:}

Study Design

An exploratory, qualitative, descriptive research design, including semi-structured interviews with seven school age children on a pediatric oncology service was used to address the following research questions.

1. What are children's perceptions of nurses who they see as approachable on an inpatient pediatric oncology unit?

2. How do children describe nurses who they feel are approachable?

Semi-structured interviews were selected in order to obtain a description and understanding of the behaviors of an approachable nurse from a child's point of view and in his or her words without imposing structure or strict guidelines in collecting the data (Marecek, 2003; Marecek, Fine \& Kidder, 1997; Morse, 2011; Streubert \& Carpenter, 2007). Each child 
completed a drawing to further engage the child, expand the conversation and clarify the meaning behind the terms the children used to describe an approachable nurse.

Participants:

Participants were selected from the inpatient unit and outpatient clinic of the oncology service of a 118-bed pediatric teaching and medically affiliated hospital in New England. The inpatient unit had approximately 16 oncology patients and a patient-nurse ratio of about 1:4 and the outpatient clinic served from 15-20 children per day with a staff of about five nurses. Purposeful sampling (Kuzel, 1999) was used to select school age children who had been diagnosed with a form of cancer, were proficient in English, medically stable, had been hospitalized at least once previous to the interview and were not cognitively or developmentally impaired. Charge nurses obtained consent to contact from the parents, after which the researcher made contact and met with potential participants and parents to discuss the aim of the study and invite their participation. There was no hesitancy on the part of any child or parent to participate. All of the children expressed an immediate desire to talk and parents responded with a quick "of course," "sure" or "no problem," as they signed their consent.

Participants included seven children between the ages of 8-12 years old including an 8,9, 10 and 11-year-old and three children who were 12 years old and four of whom were girls and three boys. Six of the seven had endured multiple hospitalizations related to their diagnosis of cancer. Diagnoses of children in the sample included osteogenic sarcoma, acute lymphocytic leukemia, non-hodgkin's lymphoma, t-cell lymphoma and alveolar rhabdomyosarcoma. Ethical Considerations:

The institutional review boards at the respective hospital and university approved the study. Signed consent was obtained from the parents and assent from the children. Since 
children are a vulnerable population, every attempt was made to provide a comfortable

environment and to secure and protect all of the children participating in the study (Polit \& Beck, 2012). The children were allowed to choose a pseudonym at the onset of the interview to be used to protect confidentiality. The listing of names associated with assigned pseudonyms was recorded on another piece of paper and kept separate from the rest of the study data. A code number and pseudonym were identified and attached to each interview. Conversations took place in a kind and casual manner allowing the child to speak freely and securely with five of the children's parent present, based on the desires of both the parent and child. The fluidity and honesty of the conversation did not differ in relation to the presence or absence of the parent. Data Collection

An interview guide, consisting mainly of cognitively and developmentally appropriate open ended questions, was used to address the research questions and allow the child to take the lead. Questions were rephrased during the interview based on the child's level of understanding and to assure that the term "approachable" was well understood. For example, the word approachable was exchanged with "easy to talk to." Probes were also used, such as, "for the nurses who are the easiest to talk to, what do they do and how do they act that makes you feel comfortable?" "How do you think nurses should behave, act and talk to kids in the hospital?"

Three of the interviews were conducted in the child's hospital room and four in the clinic by the first author, a pediatric clinical nurse specialist with 28 years of experience. Before the interview began, the researcher interacted informally with the parent and child to develop a sense of trust and promote a relaxed, non-threatening environment. All of the children were eager to talk but based on each child's personality and current state of health, enthusiasm during the interview differed. For the shy and possibly ill child, an expression of quiet cooperation persisted 
while the animated and possibly stable child engaged with excitement. Drawing, often referred to as a universal language for children, aided in reinforcing and enhancing the development of rapport (Rubin, 1984). All of the children interviewed were willing and interested in coloring. The thoughts, beliefs, fears and inner world of children can be expressed through drawing. The critical piece was the discussion that surrounded the drawing. The experiences of these children and their perceptions of an approachable nurse were often expanded and more fully illuminated as the children talked about their drawings. Drawing created a time wherein the child and researcher were able to bond and the perceptions of the child on approachability were shared in a very simple yet effective and playful manner. The interviews lasted anywhere from 40 minutes to 1 hour over the course of approximately $4 \frac{1}{2}$ months.

Data Analysis

Content analysis, including two organizing styles (immersion/crystallization and editing), was used to analyze the interviews (Crabtree \& Miller, 1992). After the interviews were transcribed by a medical transcriptionist, they were checked for accuracy and comprehensiveness by the researcher while listening to the audiotapes. A text was completed for each child. It included the transcribed interview and the researcher's journal notes. As noted earlier, the children's drawings were not analyzed but used to gain a greater understanding of their responses in the interview. The first step of analysis began with immersion/crystallization, which involves an initial reading and immersion in the text in order to obtain a sense of the whole situation and illuminate any emergent insights. (Crabtree \& Miller, 1992). It was during this step that it became apparent that even though the children had very different personalities and intellectual abilities, there were characteristics and behaviors that the nurses they saw as approachable all shared in common. In the second step, the editing organizing style, codes were 
identified for the children's descriptions of an approachable nurse and each was labeled using the children's words. The interviews were then coded within and then across participants. In each step, the researchers began by separately reading and analyzing each individual interview before completing an initial cross case analysis. Subsequently the researchers met multiple times to discuss and complete the analysis and confirm the findings.

\section{Trustworthiness}

In 1985, Lincoln and Guba developed one of the most well-established set of criteria, credibility, dependability, confirmability and transferability, for evaluating the trustworthiness of qualitative research(:omcp;m \& Guba, 1985). In this study, audio recordings and verbatim transcriptions of interviews were used to enhance credibility. Interviews were conducted until data saturation was reached and the data were analyzed separately by two researchers to enhance dependability. The children's words were used to identify and label codes and multiple quotations were presented in the findings to establish confirmability. The comments from the children were noted in association with their self-determined pseudonyms to assure confidentiality. Lastly, an effort was made to provide sufficient detail so the reader can evaluate the findings and potential applicability to enhance transferability.

\section{Findings}

The results of these interviews elicited insights from the children that were both sincere and genuine regarding their perceptions of the approachable nurse. The following findings are presented first in terms of the children's general perception of approachable nurses on the unit. Secondly, the words the children used to describe an approachable nurse are delineated and their meaning discussed. The findings are presented in a way that brings forth both the unique personalities and verbatim impressions of the participants. 
The children in this study recognized that the nurses who were approachable created an environment as one of cheer and optimism. As Dan commented, "the nurses here smile and make me feel like the hospital is like my home." For Jayson and Carley the nurses on the unit were like their "second family." Jayson "felt welcomed (on the unit). I felt like I was destined to go there." The children often used the term "feeling comfortable" while in the hospital.

Each child had a distinct personality, way of speaking and individual family context. At the same time, all of the children seemed to expect that nurses who were approachable and easy to talk to, would approach them regularly. The children had to remain in their rooms much of the time due to neutropenic precautions and infusions of chemotherapy or just not feeling well. Hobbs mentioned that nurses come in regularly, "they do it a lot, to check in on you and make sure you are doing okay" and they understand that "sometimes you feel lonely because you want to go home even though you know that there are people around you." The children felt that the nurses who came into their room, cared and took the time to know them. As Max said, "I know the nurses that usually give me the medicine, whenever we come in, and they say hi and when I know the people who are doing anything and they also know some stuff about me, they have conversations with me that aren't awkward and everything" and this "makes the nurse seem more like a friend than a nurse." Jayson stated that approachable nurses "should always know how the kid is feeling. If the kid is feeling sad, they can help with that. If the kid is happy, they could play a game with them." According to Hobbs nurses should know "children are not always happy even if they look happy...Like you might not feel good but you try to like not, not feel good even when you have the medicines that are going to try to help you feel better."

The children were asked to describe in detail the characteristics and behaviors of approachable nurses. They spoke of these nurses as smiling and happy, playful, ones who talk 
and listen to you and are creative and competent. The following descriptors and meanings were extracted from the interviews with the children.

\section{Approachable Nurses are Smiling and Happy.}

From the voice of every child interviewed came the declaration that an approachable nurse is always "smiling and happy." The smile, happy face and demeanor welcomed every child to interact. Six of the seven children said that the first time they met their favorite nurses they remembered them as "smiling and happy." Jayson summed this feeling up well as he said, "They would always smile. Always! They were never sad. They never frowned. They were just always happy...that made me feel welcomed and happy to be here." When discussing her drawing of the perfect nurse who is easiest to talk to, Riley said "I like to see people with a smile on their face all the time. It makes me feel more comfortable to talk to them and that's what I feel." Of the seven drawings, six included a nurse with a smile. As Dan expressed, "I think when a person is smiling, you feel less tense and scared. It makes it easier to talk to them because they seem happy." The children were asked to describe how a nurse should act and behave with children in the hospital. Max responded that "always having a smile helps make the kids happier...so it's not like a sad place." Riley was able to identify the importance of the child smiling also as the interaction is reciprocal and believes the nurses will be more likely to smile if the child is happy. When she is home, Hobbs thinks about the nurses because they are always happy. Hobbs noted that the smile needs to be authentic as she described a student nurse who "would try to be too happy and perky and it kinda got a little annoying after a while. They should just be themselves... and not smile all the time because that's annoying." Clearly, these children are more likely to approach a nurse who is smiling and happy as they describe this as an open invitation to interact. 


\section{Approachable Nurses are Playful.}

All seven children expressed the feeling of great joy in the hospital when the nurses were "fun and funny" and found these nurses easy to approach. They described the nurses as often telling jokes, "pulling pranks" or just having fun. They forgot that they were in the hospital when they were having fun and laughing. Without a doubt, the laughter lessened the tension and made the children feel welcome and at ease, one even said he felt "at home." Riley said that when the nurses make things fun and easier to do like taking medicines it "makes me feel like they care a lot and they want to help you take the medicine." Five of the children spoke of one of the nurses who was always funny. As Riley said "He makes me feel the most comfortable because he's funny. He makes me feel good inside." Jayson and Hobbs recalled how this nurse allows them to squirt him with needless syringes filled with water. Jayson said "He's funny. $\mathrm{He}$ would sometimes come in with a syringe with water and squirt it but not at me so I had got a syringe with water and squirted it at him." Dan drew a picture of this nurse as his favorite and said "He has a big grin and is always happy and funny. I think the perfect nurse should be kind, funny, friendly and the opposite of serious." Kris said "I like funny people. I don't like people that are kind of boring and they don't really do much stuff and they are kind of grumpy." Max spoke of another nurse who "would tell stories that are funny" and "his stories were funny and made us smile a lot" while Carley liked "fun nurses" who "usually danced to the Lion King songs" in her room. Hobbs remembered fun in the garden outside when she had "water gun fights on a nice day" and when she sees a nurse walk in with a smile and colorful scrubs with patterns, she thinks to herself "They are fun." Without a doubt, these children perceived nurses who have a sense of humor and bring laughter, fun and play into their hospital day as those who successfully diminish tension and enable approachability, comfort and conversation. 


\section{Approachable Nurses "talk and listen."}

The children reported that they want nurses to tell them what they are doing before they are doing it and while it is taking place. Talking and listening to the child helped to establish a relationship and showed genuine concern that the nurse cared and wanted to help. The children found nurses most approachable who were able to speak in a "calming way," were not rushed but in control. The children seemed to get a sense that when the nurses took the time to listen to them and "really show they care" by helping with the little things, they felt the nurses truly understood them and how they felt. The children enjoyed talking to nurses with similar interests. As Max said "it is nice to talk to a nurse who has things in common with me." This created a bond and a connection with the nurse. Hobbs enjoyed time talking to the nurses because she said it made her feel less lonely and when the nurses talked to her it made her "feel good inside because I am not just their patient, I can talk to them. I am not just a kid in the hospital. I am someone. I can talk to them and they can talk to me.” Jayson and Dan spoke of time spent playing a game or just talking with their favorite nurse because they were able to share things that bothered them like losing his hair. An approachable nurse was also one who the children reported was genuinely happy to talk to them and see them. Max said about his favorite nurse "he'll talk to us and we'll have conversations and when we get admitted, he'll usually, even if he's not our nurse, come from a different pod to say hi." There is no question that these children could sense the difference between someone who truly exhibits concern versus another who is there just to do the job. Kris said "I certainly don't need any nurses coming in that don't really feel like coming in.” 


\section{Approachable Nurses are Creative and Competent.}

Appearance was mentioned by a few children who found that colorful scrubs and clogs invited interaction with a nurse. Max said "When they are wearing scrubs, I like pictures on it because it shows you a little about them and what they like in their clothes and this is the type of person who would go up to you and start a conversation... that makes them approachable." For Hobbs, when she sees a nurse who is wearing colorful scrubs with patterns and clogs with prints, she thinks right away "that they are fun." Kris found when the nurse brought her a popsicle, it was welcoming. Jayson spoke of the "little things" his favorite nurse did to creatively help him. He spoke of hitting his port-a-cath needle into his lunch tray and this nurse took the time to create "a blocker so that when I bumped it, it wouldn't push my needle and I decorated it because I love to do artsy stuff." This same nurse helped Jayson to create a soft bird's nest with his lost hair for the baby owls in his backyard. Nurses who showed they cared by going above and beyond the tasks to complete in a shift were most approachable and easiest to talk to. While hospitalized it was important to all of these children that nurses understand that the child does not want to be in pain so they need to answer call lights and "get the pain medicine fast." Kris described her drawing of the perfect nurse, an imaginative unicorn, as one "who can fly so it can get stuff like medicine really fast." The children could perceive when a nurse was competent and confident in care and this made that nurse desirable and the child feel safe and well cared for. Carley said she felt safe with the nurse who was able to help her quickly when she was having an allergic reaction to a platelet transfusion and couldn't breathe and then another who she described as "a very good nurse...doing everything perfect for her patients." Dan was able to acknowledge the importance of competence as he was affected by the lack of it while in the emergency room and said "the only problem with the port is when you go to the ER and I have a 
new nurse who does not know how to access it. That is a problem." The perceptions of these children revealed significant insight and a great awareness that they observed, understood and have a voice.

\section{Discussion}

Similar to earlier studies on the communication between pediatric nurses and children, the children in this study wanted to be heard and they were able to describe and reflect on their experiences with nurses in a hospital setting (Coyne, 2006 \& Coyne \& Kirwan, 2012). The two major points of discussion to follow relate to the concept of approachability and the descriptors surrounding the concept of an approachable nurse. The finding that the smiling and happy face is associated with an approachable nurse adds further empirical support to the results of Campbell et al. (2010), Miles (2009), Willis et al., (2011), and Willis et al. (2013) and extends its scope beyond adults in a laboratory setting to children in a natural setting, here being a pediatric oncology inpatient unit. Additionally, all of the children had had actual contact with at least one approachable nurse and agreed that a nurse who is happy is approachable. These children were not presented with photos, as was done in the laboratory studies, but based judgement decisions on the behaviors and appearance of the nurses who cared for them. In earlier research, Willis et al. (2011) had determined that facial expressions were most significant when adults judged the approachability of another person. Researchers compared body language to that of facial expressions and determined that when the adult subjects were presented with the decision of who to approach, the judgement was made primarily on the nonverbal cues of the face as opposed to remaining body language. Similarly, the hospitalized children interviewed in this study noted the smile on the face of the nurse as one of the most important indicators that created a feeling of comfort and openness to conversation. 
Approachable nurses were described by children in different ways as "funny and competent" establishing the perception that different nurses with different personalities were all approachable in their own distinctive way. Similar to the way in which Hobbs described "not scary," the descriptions provided by the children interviewed cited a nurse who was kind and open in a non-threatening way. Several of the descriptors that were briefly noted in the literature on child-nurse communication were identified also by the children in this study. For example, Pelander, Leino-Kilpi and Katajisto (2007), found that children described nurses who were kind and cheerful as easiest to talk to, similar to the comment by Kris who said nurses should "talk kindly" (Pelander et al., 2007). Friendly, nice and humorous were characteristics noted by Lambert, Glacken and McCarron (2008). Both Jayson and Dan described approachable nurses as "friendly" and the use of "nice" was unanimously used by all of the children in this study. The terms "fun and funny" were also common within the children interviewed in regards to nurses who were easy to talk to. Pelander et.al.(2007) brought forth the characteristics of "gentle, patient and supportive." Kris, in her drawing of the unicorn as the perfect nurse, described being "gentle" as an attribute, while Riley expressed the need for the nurse to be patient while giving the child time to take medications and calm down so not to be rushed. Jayson described his favorite nurse as supporting him "through the tough times." In 2012, Coyne and Kirwan recognized similar characteristics of "nice, kind, gentle, caring and funny" along with being a good listener and responding to requests for help and call lights as significant factors that children found important in a nurse while hospitalized. Hobbs, Riley and Kris mentioned the importance of responding as quickly as possible to call lights and the need for pain medication. While these researchers were not deliberately focused on the concept of approachability, the alignment of terms children used in to describe their hospital experiences 
with those found in this study adds further credibility to an initial description of an approachable nurse, one that can be used as a basis for future research.

\section{Research Implications:}

This is the first research study to explore school age children's perceptions of approachable nurses in an inpatient setting. The finding illuminates the importance of approachable nurses and brought out the value of hearing the voice of the school age hospitalized child. There is a need for further work to explore the impact of an approachable nurse, e.g. on the children's tolerance of painful procedures and on atraumatic and family centered care. Ultimately, future research and theoretical understanding of the concept of approachability can contribute to knowledge development surrounding therapeutic communication and to advancing clinical practice

Further knowledge is needed on the approachability of nurses with hospitalized children with other chronic conditions as well as those with acute, short term hospital stays. The children interviewed carried a diagnosis of cancer which can convey a sense of mortality; creating different perceptions based on innate fears, whereas other chronic diagnoses that are not life threatening may eliminate unsaid concerns. Additionally, the impact of approachability may be greater for children over longer hospital stays whereas children sustaining short stays may not be as affected. Children with short term diagnoses and who are hospitalized for a one time illness or procedure that is quickly resolved may have perceptions of nurses that could revolve around the few nurses encountered during one hospital stay which may be positive or negative but based on a very short hospital experience

The culture of nursing can differ based on units within the same children's 
hospital and certainly from hospital to hospital based on the personality, educational preparation and experience of nurses, priorities for care and expectations held by hospital administrators and nurse managers for practice. Children's hospitals focus care completely around the needs of the child whereas general health care facilities provide care across a wide spectrum of ages and diagnoses. Nurses who float or are per diem within a children's hospital, may change unit specialty but remain with a pediatric focus whereas the same nurses in a general care hospital may have a different knowledge base and communication skills if transferring from an adult or geriatric unit to a pediatric floor, therefore creating significantly different perceptions from children of the approachable nurse. Nurses who have little knowledge and experience with ill children or children in general, may not have the communication skill needed to be approachable.

There is also a need to expand this avenue of research to hear the voice of the pediatric nurses in relation to their perceptions of approachability. Similar qualitative work could advance knowledge and create insight into the characteristics and behaviors pediatric nurses think and feel are approachable. It may be beneficial to conduct research with nurses on different units within the same children's hospital and compare data amongst nurses within an alternate pediatric health care facility and then contrast with those in a general care hospital. Factors that might influence a nurse's level of approachability include education, priorities, knowledge in pediatric growth and development, and personal expectations of nursing excellence. Perceptions of nurses may differ and therefore impact communication.

\section{Clinical Implications}

There are a number of implications that can be considered in clinical practice when communicating with a child in the hospital. Findings in this study can potentially be used to 
address problematic issues in the literature related to the consequences of negative communication. Staff nurses engage with children frequently throughout the inpatient stay. Nurses are the only providers that remain with the children throughout hospitalization and therefore one would expect that nurses will advocate and meet the child's needs. According to the many theories of growth and development, children go through stages. Language and cognition develop as children mature and it is generally expected that a priority of pediatric nurses is to be knowledgeable and sensitive to the developmental stage of the child, understanding fears and concerns (Hockenberry \& Wilson, 2011).

Findings in this study may be useful in addressing non-therapeutic communication patterns that have been described in the literature (Coyne \& Gallagher, 2011; Jepsen et al., 2019; Pena \& Juan, 2011). The descriptions of approachable nurses in this study may serve as exemplars for consideration in building awareness, establishing competencies or developing workshops to enhance communication with hospitalized children.

In 2012, Coyne and Kirwan argued that children's opinions and experiences of hospitalization are essential for monitoring and evaluating the effectiveness of health services provision. The school age children in this study and others (Corsano et al., 2015; Coyne, 2006; Pena \& Juan, 2011) have demonstrated their awareness, willingness and ability to articulate perceptions of the care they received during hospitalization. It may be time to consider systematically adding their voice, along with at of their parents, to standardized evaluations of patient care and satisfaction. To do so would require careful attention to the use of "child friendly" language. Some of the current descriptors identified in this and other research studies (Babieri, et al., 2016; Boztepe et al., 2017) could help inform such an effort. 


\section{Limitations}

As with all qualitative research, the findings are not meant to be generalizable. The participants were limited to a very small number of school age children on an oncology unit in one pediatric teaching hospital in New England and all the children were Caucasian with the exception of one boy from India. If more hildren were selected from different ages and developmental levels, e.g. early childhood, preschool or adolescence, it is highly likely that their perceptions would be different.

Access to subjects became a limitation related to the availability of school age children, 6-12 years of age within the six month time frame of the study. A full year or more may have provided a greater number of inpatient children within the school age group and not necessitated recruiting children from the outpatient clinic. The predictability of recruitment of children within this age group is variable. Additionally, in hospital interviews had to be interrupted at times to accommodate needed treatment. With a quick restatement of previous questions and discussion topic, however, these children were able to return to the topic of the interview.

\section{Conclusions}

The school age children in this study had experiences with more than one approachable nurse during their stay on an oncology unit. In their own words, they described approachable nurses as smiling and happy, playful, creative, competent and would talk and listen to them. 


\section{Funding}

This work was supported by the School of Nursing, Rhode Island College, U.S.A.

\section{CRediT Authorship contribution statement}

Bethany J. Coia: Conceptualization, formal analysis, funding acquisition, investigation, methodology, project administration, resources, writing - original draft. Donna

Schwartz-Barcott: Conceptualization, formal analysis, methodology, supervision, writing - review \& editing.

\section{References}

Barbieri, G.L., Bennati, S., Capretto, S., Ghinelli, B. \& Vecchi, C. (2016). Imagination in narrative medicine: A case study in a children's hospital in Italy. Journal of Child Health Care, 20(4), 419-427. Doi: 10.1177/1367493515625134.

Boztepe, H., Cinar, S. \& Ay, A. (2017). School-age children's perception of the hospital experience. Journal of Child Health Care, 21(2), 162-170. doi:10.1177/1367493517690454.

Campbell, D., Neuert, T., Friesen, K., \& McKeen, N. (2010). Assessing social approachability: Individual differences, in-group biases, and experimental control. Canadian Journal of Behavioral Science, 42(4), 254-263.doi: 10.1037/a0020229.

Corsano,P., Cigala,A., Majorano, M., Vignola,V., Nuzzo, M.J., Cardinale, E. \& Izzi, G. (2015). Speaking about emotional events in hospital: The role of health-care professionals in children emotional experiences. Journal of Child Health Care,19(1), 84-92.doi $10.1177 / 1367493513496912$.

Coyne, I. (2006). Children's experiences of hospitalization. Journal of Child Health Care, 10(4). 326-336. doi: 10.1177/1367493506067884.

Coyne, I. \& Gallagher, P. (2011). Participation in communication and decision-making: Children and young people's experiences in a hospital setting. Journal of Clinical Nursing, 20, 23342343. doi: 10.1111/j.1365-2702.2010.03582.x.

Coyne, I., \& Kirwan, L. (2012). Ascertaining children's wishes and feelings about hospital life. Journal of Child Health Care, 16(3), 293-304. doi: 10.1177/1367493512443905.

Crabtree, B. F., \& Miller, W. L. (1992). Doing qualitative research: multiple strategies. Thousand Oaks, CA: Sage Publications.

Hockenberry, M. J. \& Wilson, D. (2011). Wong's nursing care of infants and children (9th ed.). St. Louis, MO: Mosby. 
Jepsen, S. L., Haahr, A., Eg, M. \& Jorgensen, L.B. (2019) Coping with the unfamiliar: How do children cope with hospitalization in relation to acute and/or critical illness? A qualitative metasynthesis. Journal of child health care, 23(4).534-550. doi: 10.1177/1367493518804097.

Kuzel, A. J. (1999). Sampling in Qualitative Inquiry. In B. F. Crabtree \& Miller eds., (Handbook of Qualitative Research) $2^{\text {nd }}$ ed. (pp. 1346). Thousand Oaks: Sage Publications.

Lambert.V., Glaken, M. \& McCarron, M. (2008). "Visibleness:” The nature of communication for children admitted to a specialist children's hospital in the Republic of Ireland. Journal of Clinical Nursing, 17, 3092-3102. (https://doi.org/10.1111/j.1365-2702.2008.024262.x (in press).

Lincoln, Y. \& Guba, E. (1985). Naturalistic inquiry. Newbury Park, CA: Sage Publications.

Marecek, J. (2003). Dancing through mindfields: Toward of a qualitative stance in psychology. In P.M. Camic, J.E. Rhodes, \& L. Yardley (Eds.), Qualitative research in psychology: Expanding perspectives in methodology and design (pp.49-63) Washington, DC: APA.

Marecek, J., Fine, M., \& Kidder, L. (1997). Working between worlds: Qualitative methods and social psychology. Journal of Social Issues, 53(4), 631-644. doi:10.1111/j.1540-4560.1997.tb02452.x.

Miles, L. (2009). Who is approachable? Journal of Experimental Social Psychology, 45, 262266. doi:10.1016/j.jesp.2008.08.010.

Morse, J.M. (2011). What is qualitative health research? In N.S. Denzin \& Y.S. Lincoln (Eds.), The SAGE handbook of qualitative research (pp. 401-414) $\left(4^{\text {th }}\right.$ ed.). Los Angeles, CA: Sage.

Penlander, T., Leino-Kilpi, H., \& Katajisto, J. (2007). Quality of pediatric nursing care in Finland-Children's perspective. Journal of Nursing Care Quality, 22(2), 185-194 (doi: 1.1171.19 in press).

Pena, A. \& Juan, L. (2011). The experience of hospitalized children regarding their interactions with nursing professionals. Revista Latino-Americana de Enfermagem, 19(6): 1429-36.

Polit, D., \& Beck, C. (2012). Nursing research: Generating and assessing evidence for nursing practice. Philadelphia: Lippincott, Williams \& Wilkins.

Rubin, J. (1984). Child art therapy: Understanding and helping children grow through art ( $2^{\text {nd }}$ ed.). New York: Van Nostrand Reinhold. 
Soderback, M., Coyne, I. \& Harder, M. (2011). The importance of including both a child perspective and the child's perspective within healthcare settings to provide truly childcentered care. Journal of Child Health Care, 15(2), 99-106. doi: 10.1177/136749351039764.

Streubert, H. J., \& Carpenter, D. R. (2007). The conduct of qualitative research: Common essential elements. In Qualitative research in nursing: Advancing the humanistic imperative (5th ed., pp. 18-33). Philadelphia, PA: Lippincott, Williams \& Wilkins.

United Nations Children's Fund, UNICEF. (2003). The state of the world's children. New York and Geneva: UNICEF.

United Nations Convention on the Rights of the Child, UNCRC. (1989). Convention on the rights of the child. Geneva: United Nations.

UN General Assembly on Children. (2002). Special session of the UN Assembly on children. Retrieved from http://www.unicef.org/specialsession/.

Willis, M., Dodd, H., \& Palermo, R. (2013). The relationship between anxiety and the social judgments of approachability and trustworthiness. PLOS ONE, 8(10), e76825. doi: 10.1371/journal.pone.0076825.

Willis, M., Palermo, R. \& Burke, D. (2011). Judging approachability on the face of it: The influence of face and body expressions on the perception of approachability. Emotion, 11(3), 514-523. doi:10.1037/a0022571. 